\title{
Purification and Characterization of Melanogenic Enzyme Tyrosinase from Button Mushroom
}

\author{
Kamal Uddin Zaidi, ${ }^{1}$ Ayesha S. Ali, ${ }^{2}$ and Sharique A. Ali ${ }^{2}$ \\ ${ }^{1}$ Molecular Biotechnology Laboratory, Centre for Scientific Research \& Development, People’s University, Bhopal 462010, India \\ ${ }^{2}$ Department of Biotechnology, Saifia College of Science, Bhopal 462001, India \\ Correspondence should be addressed to Ayesha S. Ali; drayeshariqali@yahoo.com
}

Received 14 May 2014; Revised 18 July 2014; Accepted 23 July 2014; Published 14 August 2014

Academic Editor: Denise Freire

Copyright ( 2014 Kamal Uddin Zaidi et al. This is an open access article distributed under the Creative Commons Attribution License, which permits unrestricted use, distribution, and reproduction in any medium, provided the original work is properly cited.

\begin{abstract}
Melanogenesis is a biosynthetic pathway for the formation of the pigment melanin in human skin. A key enzyme, tyrosinase, catalyzes the first and only rate-limiting steps in melanogenesis. Since the discovery of its melanogenic properties, tyrosinase has been in prime focus and microbial sources of the enzyme are sought. Agaricus bisporus widely known as the common edible mushroom, it's taking place in high amounts of proteins, enzyme, carbohydrates, fibers, and low fat contents are frequently cited in the literature in relation to their nutritional value. In the present study tyrosinase from Agaricus bisporus was purified by ammonium sulphate precipitation, dialysis followed by gel filtration chromatography on Sephadex G-100, and ion exchange chromatography on DEAE-Cellulose; the enzyme was purified, 16.36 -fold to give $26.6 \%$ yield on total activity in the crude extract and final specific activity of $52.19 \mathrm{U} / \mathrm{mg}$. The SDS-PAGE electrophoresis showed a migrating protein band molecular weight of $95 \mathrm{kDa}$. The purified tyrosinase was optimized and the results revealed that the optimum values are $\mathrm{pH} 7.0$ and temperature $35^{\circ} \mathrm{C}$. The highest activity was reported towards its natural substrate, L-DOPA, with an apparent $\mathrm{Km}$ value of $0.933 \mathrm{mM}$. This indicated that tyrosinase purified from Agaricus bisporus is a potential source for medical applications.
\end{abstract}

\section{Introduction}

Tyrosinase (E.C. 1.14.18.1) is a ubiquitous enzyme involved in pigmentation. It catalyzes hydroxylation of monophenols (cresolase activity) and oxidation of diphenols (catecholase activity) in the presence of molecular oxygen. The conversion of phenols to $o$-diphenols by tyrosinase is a potentially attractive catalytic ability and thus tyrosinase has attracted a lot of attention with respect to its biotechnological application as the catechol products are useful as drugs or drug synthons, for example, L-DOPA [1]. It also plays an important role in the formation of melanin pigment during melanogenesis in melanocytes which are located at the epidermal junction and it is present in these cells that originate from the embryonic neural crest and is responsible for the synthesis of melanin. [2] It was first characterized in mammals for its role in the development of melanomas and for implication in pigmentation troubles such as albinism and vitiligo [3]. The physiological role of tyrosinases is related to melanin biosynthesis and has been extracted from different sources such as fungi, fruits, and mammalian melanoma tumors [4, 5]. In fungi, melanins are involved in defence mechanisms against stress factors such as UV or gamma radiation, free radicals, dehydration, and extreme temperatures $[6,7]$. The stability of fungal spores also benefits from the protective role of melanin [8]. In addition, tyrosinases are associated with wound healing, with the immune response in plants $[9,10]$. In humans, tyrosinase is involved in the pigmentation in melanocytes [11-13], as a marker in melanoma patients [14] and as a target for the activation of prodrugs [15]. In the present work, as an initial step in evaluating the pharmaceutical potential of the tyrosinase of mushroom Agaricus bisporus, we undertook a preliminary characterization of the enzyme. The characterized tyrosinase showed very high similarities compared to human tyrosinase; this indicated that purified and characterized mushroom can be a prosperous source of tyrosinase for therapeutic use in melanogenesis. 


\section{Materials and Methods}

2.1. Preparation of Tyrosinase. Extraction of mushroom tyrosinase was performed by the method of Kamahldin et al. [16], with few modifications. The sliced mushrooms were homogenized by waring blender. Enzyme extraction was prepared with $500 \mathrm{~mL}$ of cold $100 \mathrm{mM}$ phosphate buffer ( $\mathrm{pH}$ 5.8) for $300 \mathrm{~g}$ of mushroom. The homogenate was centrifuged at $5000 \mathrm{rpm}$ for $30 \mathrm{~min}$ and supernatant was collected. The sediments were mixed with cold phosphate buffer and were allowed to stand in cold condition with occasional shaking. Then the sediment containing buffer was subjected to centrifugation once again to collect supernatant. The supernatant was used as a source of enzyme.

2.2. Purification of the Enzyme from the Crude Extract. The purification of tyrosinase was performed by the method of Kamahldin et al. [16], with minor modification. Crude enzyme extract purified by salt precipitation, dialysis, gel filtration, ion exchange chromatography, and so forth has been employed in series so as to obtain the enzyme in its purest form. The pure enzyme thus produced can be used for the further analysis.

2.3. Ammonium Sulphate Precipitation and Dialysis. Ammonium sulphate precipitation was done in an ice bath using the finely grounded ammonium sulfate. The powder was weighed and added slowly to the extract by constant stirring to ensure complete solubility, and the solution was centrifuged at $5000 \mathrm{rpm}$ for $30 \mathrm{~min}$ at $4^{\circ} \mathrm{C}$. Different precipitation steps were carried out for tyrosinase enzyme precipitation (45$80 \%)$ and precipitates were collected. The precipitate was dialyzed against $100 \mathrm{mM}$ potassium phosphate buffer ( $\mathrm{pH} 7.0$ ) for $24 \mathrm{~h}$ by changing the buffer thrice. The dialyzed fraction was used for tyrosinase activity and protein content.

2.4. Assay of Tyrosinase Activity. The tyrosinase activity assay was performed as reported by Sung and Cho [17] spectrophotometrically, measuring conversion of L-DOPA to red colored oxidation product dopachrome. The initial rate of reaction is proportional to concentration of the enzyme. An aliquot containing tyrosinase was incubated for $5 \mathrm{~min}$ at $35^{\circ} \mathrm{C}$ at time zero, $1 \mathrm{~mL}$ of L-DOPA solution $(4 \mathrm{mg} / \mathrm{mL})$ for measured at $475 \mathrm{~nm}$. After incubation for additional $5 \mathrm{~min}$, the mixture was shaken again and a second reading was determined and was measured for 3 minutes. The change in absorbance was proportional to enzyme concentration. One unit of enzyme corresponded to the amount which catalyzed the transformation of $1 \mu \mathrm{mol}$ of substrate to product per min under the above conditions and produced 1.35 changes in absorbance. Specific activity was expressed as enzyme unit per milligram of protein. The protein content of the enzyme was determined by the method of Lowry [18], with bovine serum albumin as standard.

2.5. Sephadex G-100 Gel Filtration. The dialyzed ammonium sulfate fraction was applied to a Sephadex G-100 column that was preequilibrated with a $100 \mathrm{mM}$ phosphate buffer of
$\mathrm{pH}$ 7.0. The protein elution was done with the same buffer at a flow rate of $5 \mathrm{~mL} / \mathrm{min}$. The fractions were collected at $4^{\circ} \mathrm{C}$. It was assayed for protein at $280 \mathrm{~nm}$ as well as for enzyme activity. The active fractions were pooled, dialyzed against the $100 \mathrm{mM}$ phosphate buffer of $\mathrm{pH}$ 7.0, and concentrated.

2.6. DEAE-Cellulose Column Chromatography. Dialyzed enzyme preparation obtained after ammonium sulphate precipitation and Sephadex G-100 column was subjected to ion exchange chromatography using DEAE-Cellulose column $(20 \times 1 \mathrm{~cm})$. The dialyzed enzyme preparation was loaded on DEAE-Cellulose column which was preequilibrated with potassium phosphate buffer $(100 \mathrm{mM}$, $\mathrm{pH}$ 7.0). The column was washed first with equilibrated buffer and then bound proteins were eluted using linear gradient of 0-100 $\mathrm{mM} \mathrm{NaCl}$ and $0-100 \mathrm{mM}$ potassium phosphate buffer at a flow rate of $1 \mathrm{~mL}$ per min. The fractions $(2.5 \mathrm{~mL}$ each) were collected and assayed for tyrosinase activity and those showing high activity were pooled and used for SDS-PAGE analysis.

2.7. Sodium Dodecyl Sulfate-Polyacrylamide Gel (SDS-PAGE) Electrophoresis of Purified Tyrosinase. SDS-PAGE was performed using a $12 \%$ separating gel and $4 \%$ stacking gel. The samples were heated for $5 \mathrm{~min}$ at $100^{\circ} \mathrm{C}$ in capped vials with $1 \%(\mathrm{w} / \mathrm{v})$ SDS in the presence of $\beta$-mercaptoethanol. Electrophoresis was performed at a $125 \mathrm{~V}$ for $4 \mathrm{~h}$ in Tris$\mathrm{HCl}$ buffer of $\mathrm{pH}$ 8.3. After electrophoresis, proteins in the separating gel were made visible by staining with Coomassie Brilliant Blue R-250. The standards used to make a plot of log molecular weight versus mobility of the protein band were lysozyme $(20 \mathrm{kDa})$, myoglobin $(26 \mathrm{kDa})$, carbonic anhydrase $(38 \mathrm{kDa})$, ovalbumin $(46 \mathrm{kDa})$, glutamate $(62 \mathrm{kDa})$, bovine serum albumin $(91 \mathrm{kDa}), \beta$-galactosidase $(120 \mathrm{kDa})$, and myosin $(200 \mathrm{kDa})$.

2.8. Effect of $p H$ and Temperature on Enzyme Activity. The activity of tyrosinase was evaluated at different $\mathrm{pH}$ values in the range between $\mathrm{pH} 3$ and 10 under assay conditions and the amount of dopachrome was determined. Buffers used were citrate phosphate $(\mathrm{pH} 3.0-5.0)$, potassium phosphate ( $\mathrm{pH}$ 6.0-7.0), Tris- $\mathrm{HCl}$ ( $\mathrm{pH}$ 8.0-9.0), and glycine- $\mathrm{NaOH}$ (pH 9.0-10). Optimum temperature for enzyme activity was determined by incubating the standard reaction mixture at temperatures ranging from 35 to $65^{\circ} \mathrm{C}$.

2.9. Kinetic Analysis. The enzyme kinetics as measured by the Michaelis constant $(\mathrm{Km})$ is defined as the substrate concentration at half the maximum velocity, the rate of enzymatic reactions, by relating reaction rate to the concentration of a substrate. The Michaelis constant $(\mathrm{Km})$ value of the purified enzyme was estimated in a range of tyrosinase concentrations. The apparent $\mathrm{Km}$ value of purified tyrosinase was calculated from the Lineweaver-Burk plots relating $1 / \mathrm{V}$ to $1 /[\mathrm{S}]$. 


\section{Results and Discussion}

3.1. Partial Purification of Tyrosinase. Mushroom contains a considerable amount of various phenolic compounds, which are readily oxidized during the homogenizing process. Upon oxidation and successive polymerization of the phenolic content of the mushroom extract, macromolecules of melanins are formed. The purification of tyrosinase from mushroom is moderately more difficult due to the smaller amount of tissue available per fruiting body of mushroom and greater amount of melanin in these tissues. The accompanying melanins which are usually built up during preparation of the homogenized extract could be extensively removed from the protein mixture using ion exchange material. Initially, we tried adsorbent anion exchangers, as well as precipitation methods ammonium sulfate precipitation to remove colored material or to concentrate tyrosinase. None of these methods were successful without causing a decrease in the recovery of enzyme activity or not being able to remove a substantial amount of colored material.

Briefly, crude extracts were prepared by homogenization in $100 \mathrm{mM}$ potassium phosphate buffer $(\mathrm{pH} 5.8$ ) containing $1 \mathrm{mM}$ EDTA. After centrifugation, the supernatant was applied to ammonium sulfate precipitation. Partial purification of tyrosinase using ammonium sulfate precipitation showed that the best fraction was $70 \%$ with respect to the crude enzyme and other fractions. It gave the maximum values of total activity, specific activity, and yield of the tyrosinase enzyme which reached $11.09 \mathrm{U} / \mathrm{mg}, 83.5 \%$, respectively. The -fold purification of the purified enzyme was 3.47 when $70 \%$ ammonium sulfate was used. The previous findings were identical to that reported by Lee et al. [19], who found that $70 \%$ ammonium sulfate was the best fraction which gave the highest yield of tyrosinase activity from Solanum melongena. The dialyzed ammonium sulfate precipitate that was applied to Sephadex G-100 gel filtration column chromatography showed major peaks of tyrosinase activity which were observed in active fractions and resulted in 9.22-fold purification with a final specific activity of $29.42 \mathrm{U} / \mathrm{mg}$. The overall recovery of the purification was $35.7 \%$ (Table 1). This active fraction was applied to a DEAE-Cellulose column and eluted with a stepwise-increasing $\mathrm{NaCl}$ gradient. The enzyme was eluted at $0-100 \mathrm{mM} \mathrm{NaCl}$ (Figure 1). The eluted active fractions rechromatographed on the same column with a linear gradient of potassium phosphate buffer $(0-100 \mathrm{mM})$ were passed through the column (Figure 2). This two-step purification scheme, ion exchange chromatography, resulted in a partially purified tyrosinase preparation, obtained by pooling fractions $25,26,27$, and 28 and the enzyme was purified by about 16.36 -fold purification with a final specific activity of $52.19 \mathrm{U} / \mathrm{mg}$. The overall recovery of the purification was $26.6 \%$. Horowitz et al. [20] reported that tyrosinase that is produced in the fruiting body can be recuperated and purified by homogenizing in a blender and then passed through a French press followed by acetone or ammonium sulfate precipitation [21]. The resuspended precipitate was further purified by one or more chromatography columns. The most commonly used columns are hydroxylapatite [22], DEAE-Cellulose [23] or DEAE Sepharose [24], various other

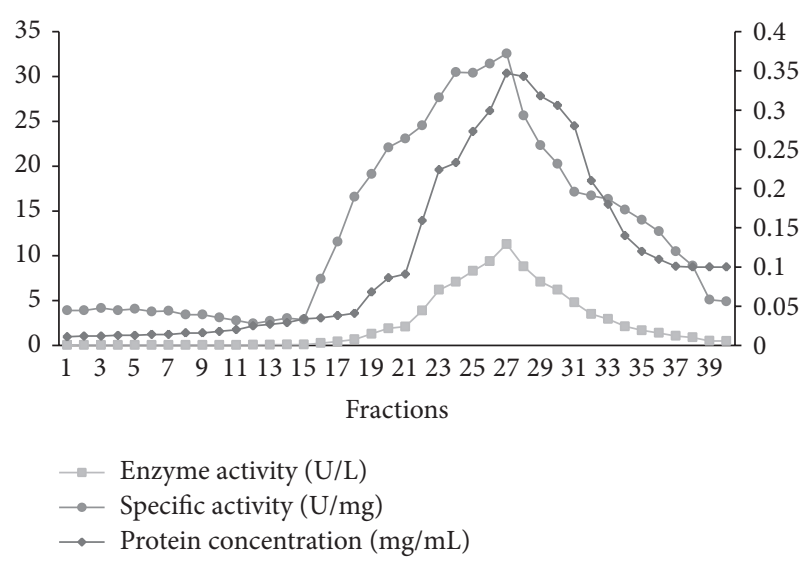

FIGURE 1: Elution profile on DEAE-Cellulose column chromatography. An aliquot of each fraction was assayed for protein content and tyrosinase activity. A linear gradient of $\mathrm{NaCl}$ was $0-100 \mathrm{mM}$.

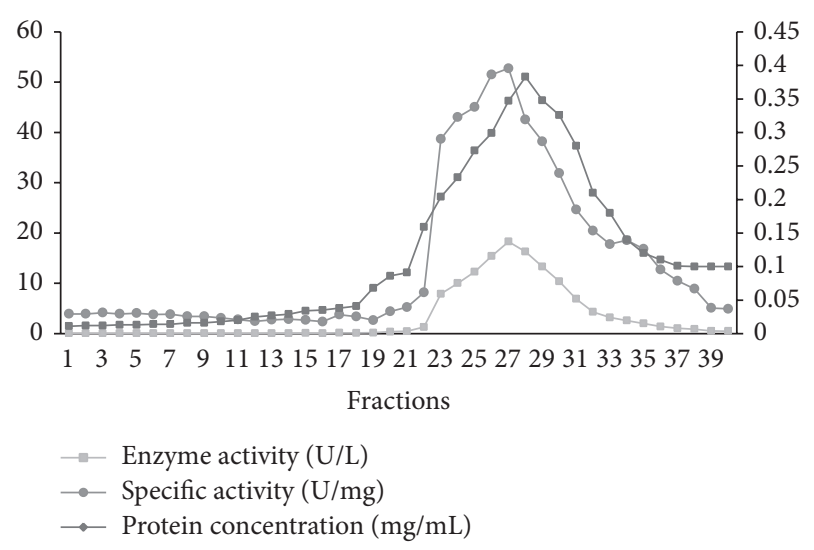

FIGURE 2: Elution profile on DEAE-Cellulose column chromatography. An aliquot of each fraction was assayed for protein content and tyrosinase activity. A linear gradient of potassium phosphate buffer was $0-100 \mathrm{mM}$.

immunoaffinity resins [25], and Sephadex size exclusion gel [21].

SDS-PAGE of the enzyme preparation from different purification steps showed that the resolved electrophoretic bands were progressively improved from the crude extract to the final step of the DEAE-Cellulose column. It revealed only a single distinctive protein band for the pure preparation of tyrosinase with an apparent molecular weight of $95 \mathrm{kDa}$ (Figure 3). In this respect, tyrosinase purified from Aspergillus oryzae, Trichoderma reesei, and Aspergillus nidulans was with smaller molecular weight in the range of $67,43.2$, and $50.48 \mathrm{kDa}$ [26-28]. Kanda et al. [29] obtained two activity peaks after ion exchange chromatography of an extract from Lentinula edodes. When the fractions corresponding to each peak were analyzed by partially denaturing SDS-PAGE, both had three bands that showed tyrosinase activity. Fully denaturing SDS-PAGE of the same fractions gave bands at 15, 49 , and $54 \mathrm{kDa}$ for one fraction and 15,50 , and $55 \mathrm{kDa}$ for 
TABLE 1: Purification of tyrosinase from mushroom A. bisporus.

\begin{tabular}{lcccccc}
\hline Fractions & $\begin{array}{c}\text { Volume } \\
(\mathrm{mL})\end{array}$ & $\begin{array}{c}\text { Total } \\
\text { protein }(\mathrm{mg})\end{array}$ & $\begin{array}{c}\text { Activity } \\
\text { (units) }\end{array}$ & Total activity U & Specific activity U/mg & -fold purification Yield (\%) \\
\hline Crude extract & 400 & 321.4 & 2.56 & 1025 & 3.189 & 1 \\
Ammonium sulphate precipitate & 120 & 77.13 & 7.13 & 856 & 11.09 & 3.47 \\
Dialysis & 60 & 33.63 & 8.25 & 495 & 14.71 & 83.5 \\
Gel filtration G100 column & 30 & 12.44 & 12.2 & 366 & 29.42 & 48.2 \\
DEAE-Cellulose column & 15 & 5.23 & 18.2 & 273 & 52.19 & 9.22 \\
\hline
\end{tabular}

DEAE: diethylaminoethyl.

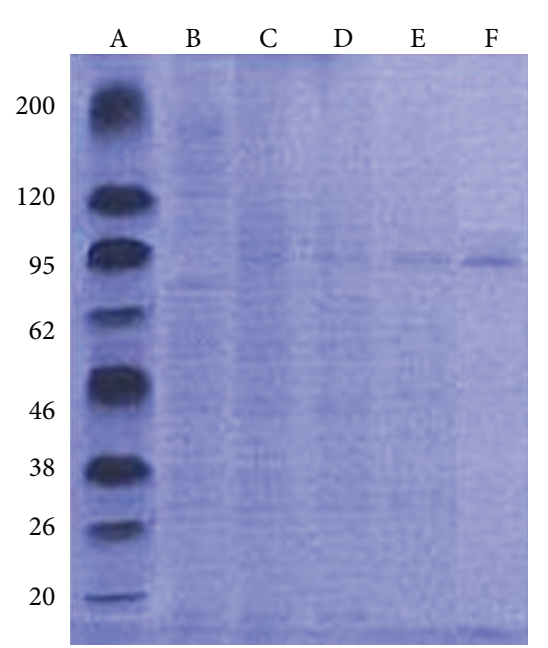

Figure 3: Polyacrylamide gel electrophoresis of tyrosinase from $A$. bisporus, lane A, standard protein of different molecular weight; lane $\mathrm{B}$, crude extract; lane $\mathrm{C}$, ammonium sulfate fraction; lane $\mathrm{D}$, dialysis; lane E, Sephadex G-100 gel filtration fraction; and lane F, DEAECellulose fraction of tyrosinase $\sim 95 \mathrm{kDa}$.

the other purified tyrosinase from Lentinula edodes [29] and exhibited a molecular weight of $105 \mathrm{kDa}$.

3.2. Properties of the Partially Purified Enzyme. The purified tyrosinase was active at a wide range of temperature from $30^{\circ} \mathrm{C}$ to $65^{\circ} \mathrm{C}$ with an optimum at $35^{\circ} \mathrm{C}$ (Figure 4), and about $35 \%$ of tyrosinase activity was still present at $55^{\circ} \mathrm{C}$, but it lost its activity at $65^{\circ} \mathrm{C}$. Our results were in agreement with a previous study which reported that the optimum temperature for tyrosinase activity obtained from Streptomyces sp. was $35^{\circ} \mathrm{C}$. Tyrosinase from Pseudomonas putida and Trichoderma reesei showed maximum activity at $30^{\circ} \mathrm{C}[27,30]$, and maximum activity of tyrosinase purified from Bacillus megaterium and Lentinula boryana was at $40^{\circ} \mathrm{C}[31,32]$.

Tyrosinases with various physicochemical features have been reported from various organisms. These enzymes generally have a $\mathrm{pH}$ optimum in the neutral or slightly acidic range. The tyrosinase from $T$. reesei and I. batatas has a basic $\mathrm{pH}$ optimum of 9 and 8 , respectively [27,33]. Results (Figure 5) revealed that $\mathrm{pH} 7.0$ was the optimal $\mathrm{pH}$ for tyrosinase from $A$. bisporus using phosphate buffer. These results coincide with that of Liu et al. [31] who reported that the maximal tyrosinase activity of Bacillus megaterium

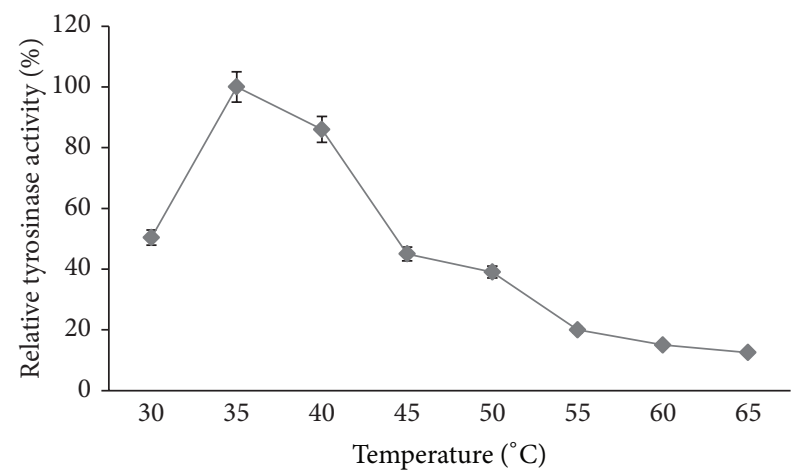

FIGURE 4: Effect of temperature on the tyrosinase activity of the crude extract prepared from A. bisporus. Data were obtained as mean value of optical density. Assays were done in potassium phosphate buffer $(100 \mathrm{mM}, \mathrm{pH}=7.0)$. The optimum activity of the sample incubated at $35^{\circ} \mathrm{C}$ was taken as $100 \%$.

was 7.0, and the optimal L-tyrosinase activity extracted from Trichoderma reesei was 9.0 [27]. The $\mathrm{pH}$-dependent changes in the kinetic properties of the mushroom tyrosinase are similar to the $\mathrm{pH}$-dependent changes in the kinetic properties of tyrosinase from B-16 murine melanoma and human skin and thus appear to be a general property of tyrosinase from diverse sources. Our results also demonstrated that tyrosinase retained about $65 \%$ of its activity after storing at $\mathrm{pH} 7.0$ for $24 \mathrm{~h}$. This means that tyrosinase of A. bisporus had higher $\mathrm{pH}$ stability over a wide range of $\mathrm{pH}$ values.

The Km value of tyrosinase was found to be $0.933 \mathrm{mM}$ shown in (Figure 6). This result indicates the high affinity of tyrosinase towards its substrate, which might relate to its degree of effectiveness against melanogenesis. Higher $\mathrm{Km}$ values 0.9 and $0.85 \mathrm{mM}$ for tyrosinase from Pycnoporus sanguineus and Lentinula edodes, respectively, have been reported $[24,29]$. On The other hand, a lower $\mathrm{Km}$ value $(0.075 \mathrm{mM})$ was obtained for tyrosinase from Bacillus megaterium [31].

\section{Conclusions}

In the increasingly ageing Western population with significant cumulative sun exposure, the control of hyperpigmentation and dyspigmentation is a significant clinical and cosmetic challenge. Factors like UVR exposure and skin inflammation have been implicated in hyperpigmentary conditions 


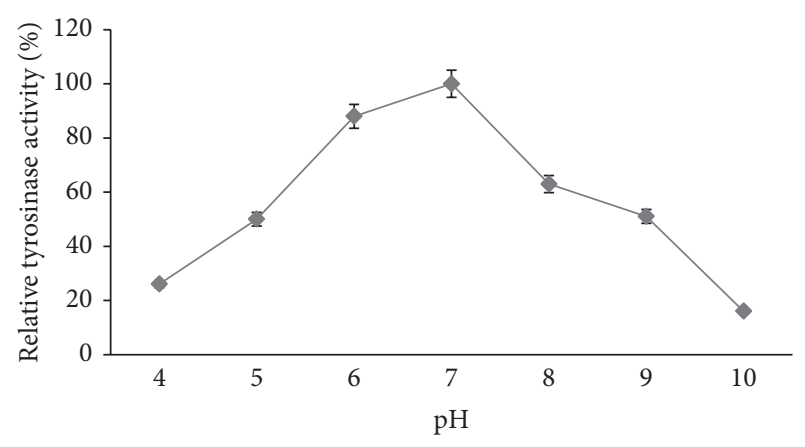

FIGURE 5: Effect of $\mathrm{pH}$ on the tyrosinase activity of the crude extract of $A$. bisporus. Data were obtained as mean value of optical density. Assays were done at $35^{\circ} \mathrm{C}$ and the activity of the sample was incubated on $100 \mathrm{mM}$ acetate buffer at $4.0-5.0 \mathrm{pH}, 100 \mathrm{mM}$ phosphate buffer at $6.0-8.0 \mathrm{pH}$, and $100 \mathrm{mM}$ Tris-HCl buffer at 9.0$10 \mathrm{pH}$. The optimum activity of the sample at $\mathrm{pH} 6.0$ was taken as $100 \%$.

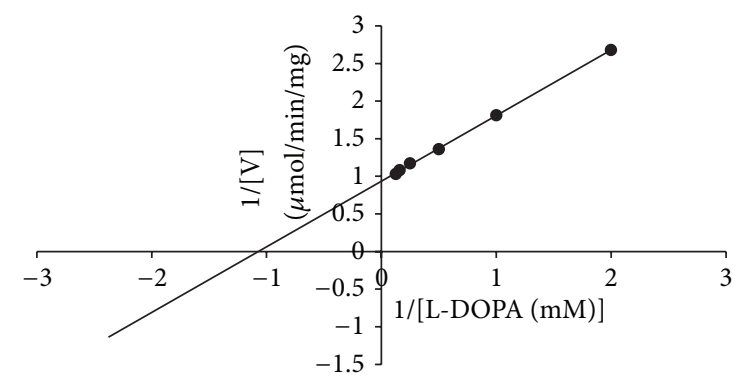

FIGURE 6: Lineweaver-Burk plot of A. bisporus tyrosinase. Data were obtained as mean value of $1 /[\mathrm{V}]$, inverse of the increase of optical density at $475 \mathrm{~nm}$ per min (OD475), of three independent tests with different concentrations of L-DOPA as a substrate.

such as melasma and solar lentigines. As dyspigmentation is viewed as a prominent marker of facial skin ageing, novel, safe, and effective agents that modulate pigmentation are being sought. A wide range of agents have been described to treat hyper- and dyspigmentation with different mechanism of action. The key enzyme that is responsible for melanin production is tyrosinase; those modulating strategies should ideally address multiple aspects of melanocyte biology in human skin cell, that is, melanogenesis (induced tyrosinase protein expression using cellular tyrosine) melanin transfer to recipient keratinocytes. From the present study, as an initial step in evaluating the pharmaceutical potential of the tyrosinase of mushroom, we undertook a preliminary characterization of the enzyme. The characterized tyrosinase showed very high similarities compared to human tyrosinase. This indicated that purified and characterized mushroom tyrosinase can be a prosperous source of tyrosinase for therapeutic use in melanogenesis.

\section{Conflict of Interests}

The authors declare that there is no conflict of interests regarding the publication of this paper.

\section{Acknowledgments}

The authors are thankful to People's University, People's Group, Bhopal, for laboratory facilities and to the Principal and Secretary of Saifia College of Science, Bhopal, for the encouragement.

\section{References}

[1] V. J. Hearing Jr., "Mammalian monophenol monooxygenase (tyrosinase): purification, properties, and reactions catalyzed," Methods in Enzymology, vol. 142, pp. 154-165, 1987.

[2] A. M. Nambudiri and J. V. Bhat, "Conversion of p-coumarate into caffeate by Streptomyces nigrifaciens. Purification and properties of the hydroxylating enzyme," Biochemical Journal, vol. 130, no. 2, pp. 425-433, 1972.

[3] P. A. Riley, "Melanin," International Journal of Biochemistry and Cell Biology, vol. 29, no. 11, pp. 1235-1239, 1997.

[4] K. U. Zaidi, A. S. Ali, S. A. Ali, and I. Naaz, "Microbial tyrosinase: promising enzymes for pharmaceutical, food bioprocessing, and environmental industry," Biochemistry Research International, vol. 2014, Article ID 854687, 16 pages, 2014.

[5] K. U. Zaidi, A. Mani, S. A. Ali, and A. S. Ali, "Evaluation of Tyrosinase producing endophytic fungi from Calotropis gigantea, Azadirachta indica, Ocimum tenuiflorum and Lantana camara," Annual Review \& Research in Biology, vol. 3, no. 4, pp. 389-396, 2013.

[6] S. Halaouli, M. Asther, J. C. Sigoillot, M. Hamdi, and A. Lomascolo, "Fungal tyrosinases: new prospects in molecular characteristics, bioengineering and biotechnological applications," Journal of Applied Microbiology, vol. 100, no. 2, pp. 219232, 2006.

[7] P. A. Riley, "Melanogenesis and melanoma," Pigment Cell Research, vol. 16, no. 5, pp. 548-552, 2003.

[8] A. M. Mayer and E. Harel, "Polyphenol oxidases in plants," Phytochemistry, vol. 18, no. 2, pp. 193-215, 1979.

[9] C. W. G. van Gelder, W. H. Flurkey, and H. J. Wichers, "Sequence and structural features of plant and fungal tyrosinases," Phytochemistry, vol. 45, no. 7, pp. 1309-1323, 1997.

[10] L. Cerenius and K. Söderhäll, "The prophenoloxidase-activating system in invertebrates," Immunological Reviews, vol. 198, pp. 116-126, 2004.

[11] S. A. Ali, T. Sultan, J. M. Galgut, R. Sharma, K. V. Meitei, and A. S. Ali, "In vitro responses of fish melanophores to lyophilized extracts of Psoralea corylifolia seeds and pure psoralen," Pharmaceutical Biology, vol. 49, no. 4, pp. 422-427, 2011.

[12] Y. Jin, S. A. Birlea, P. R. Fain et al., "Variant of TYR and autoimmunity susceptibility loci in generalized vitiligo," The New England Journal of Medicine, vol. 362, no. 18, pp. 1686-1697, 2010.

[13] K. U. Schallreuter, M. M. A. E. L. Salem, S. Hasse, and H. Rokos, "The redox-biochemistry of human hair pigmentation," Pigment Cell and Melanoma Research, vol. 24, no. 1, pp. 51-62, 2011.

[14] A. Gradilone, E. Cigna, A. M. Aglianò, and L. Frati, “Tyrosinase expression as a molecular marker for investigating the presence of circulating tumor cells in melanoma patients," Current Cancer Drug Targets, vol. 10, no. 5, pp. 529-538, 2010.

[15] S. Jawaid, T. H. Khan, H. M. I. Osborn, and N. A. O. Williams, "Tyrosinase activated melanoma prodrugs," Anti-Cancer Agents in Medicinal Chemistry, vol. 9, no. 7, pp. 717-727, 2009. 
[16] H. Kamahldin, R. J. Ferdous, K. Ali-Asghar, and S. B. Shahrzad, "Purification of tyrosinase from edible mushroom," Iranian Journal of Biotechnology, vol. 2, no. 3, pp. 189-194, 2004.

[17] C. K. Sung and S. H. Cho, "The purification and characteristics of tyrosinase from ginger," Journal of Biochemistry Molecular Biology, vol. 25, pp. 564-572, 1992.

[18] O. H. Lowry, N. J. Rosebrough, A. L. Farr, and R. J. Randall, "Protein measurement with the Folin phenol reagent," The Journal of biological chemistry, vol. 193, no. 1, pp. 265-275, 1951.

[19] J. Lee, K. Kong, and S. Cho, "Purification and characterization of tyrosinase from Solanum melongena," Journal of Biochemistry and Molecular Biology, vol. 30, no. 2, pp. 150-156, 1997.

[20] N. H. Horowitz, M. Fling, and G. Horn, "Tyrosinase (Neurospora crassa)," Methods in Enzymology, vol. 17, pp. 615-620, 1970.

[21] L. A. Mueller, U. Hinz, and J. Zrÿd, "Characterization of a tyrosinase from Amanita muscaria involved in betalain biosynthesis," Phytochemistry, vol. 42, no. 6, pp. 1511-1515, 1996.

[22] S. Bouchilloux, P. McMahill, and H. S. Mason, "The multiple forms of mushroom tyrosinase. Purification and molecular properties of the enzymes," The Journal of Biological Chemistry, vol. 238, pp. 1699-1707, 1963.

[23] Y. Fan and W. H. Flurkey, "Purification and characterization of tyrosinase from gill tissue of Portabella mushrooms," Phytochemistry, vol. 65, no. 6, pp. 671-678, 2004.

[24] S. Halaouli, M. Asther, K. Kruus et al., "Characterization of a new tyrosinase from Pycnoporus species with high potential for food technological applications," Journal of Applied Microbiology, vol. 98, no. 2, pp. 332-343, 2005.

[25] A. A. Khan, S. Akhtar, and Q. Husain, "Simultaneous purification and immobilization of mushroom tyrosinase on an immunoaffinity support," Process Biochemistry, vol. 40, no. 7, pp. 2379-2386, 2005.

[26] E. Ichishima, H. Maeba, T. Amikura, and H. Sakata, "Multiple forms of protyrosinase from Aspergillus oryzae and their mode of activation at pH 3.0," Biochimica et Biophysica Acta, vol. 786, no. 1-2, pp. 25-31, 1984.

[27] E. Selinheimo, M. Saloheimo, E. Ahola et al., "Production and characterization of a secreted, C-terminally processed tyrosinase from the filamentous fungus Trichoderma reesei," FEBS Journal, vol. 273, no. 18, pp. 4322-4335, 2006.

[28] C. E. Birse and A. J. Clutterbuck, "N-Acetyl-6-hydroxytryptophan oxidase, a developmentally controlled phenol oxidase from Aspergillus nidulans," Journal of General Microbiology, vol. 136, no. 9, pp. 1725-1730, 1990.

[29] K. Kanda, T. Sato, S. Ishii, H. Enei, and S. Ejiri, "Purification and properties of tyrosinase isozymes from the gill of Lentinus edodes fruiting body," Bioscience, Biotechnology and Biochemistry, vol. 60, no. 8, pp. 1273-1278, 1996.

[30] A. M. McMahon, E. M. Doyle, S. Brooks, and K. E. O'Connor, "Biochemical characterisation of the coexisting tyrosinase and laccase in the soil bacterium Pseudomonas putida F6," Enzyme and Microbial Technology, vol. 40, no. 5, pp. 1435-1441, 2007.

[31] Z. Liu, Y. Liu, H. Yang, Y. Yang, G. Shen, and R. Yu, "A phenol biosensor based on immobilizing tyrosinase to modified core-shell magnetic nanoparticles supported at a carbon paste electrode," Analytica Chimica Acta, vol. 533, no. 1, pp. 3-9, 2005.

[32] R. O. de Faria, V. R. Moure, W. Balmant, M. A. L. de Almeida Amazonas, N. Krieger, and D. A. Mitchell, "The tyrosinase produced by Lentinula boryana (Berk. \& Mont.) pegler suffers substrate inhibition by L-DOPA," Food Technology and Biotechnology, vol. 45, no. 3, pp. 334-340, 2007.
[33] C. Eicken, F. Zippel, K. Büldt-Karentzopoulos, and B. Krebs, "Biochemical and spectroscopic characterization of catechol oxidase from sweet potatoes (Ipomoea batatas) containing a type-3 dicopper center," FEBS Letters, vol. 436, no. 2, pp. 293299, 1998. 

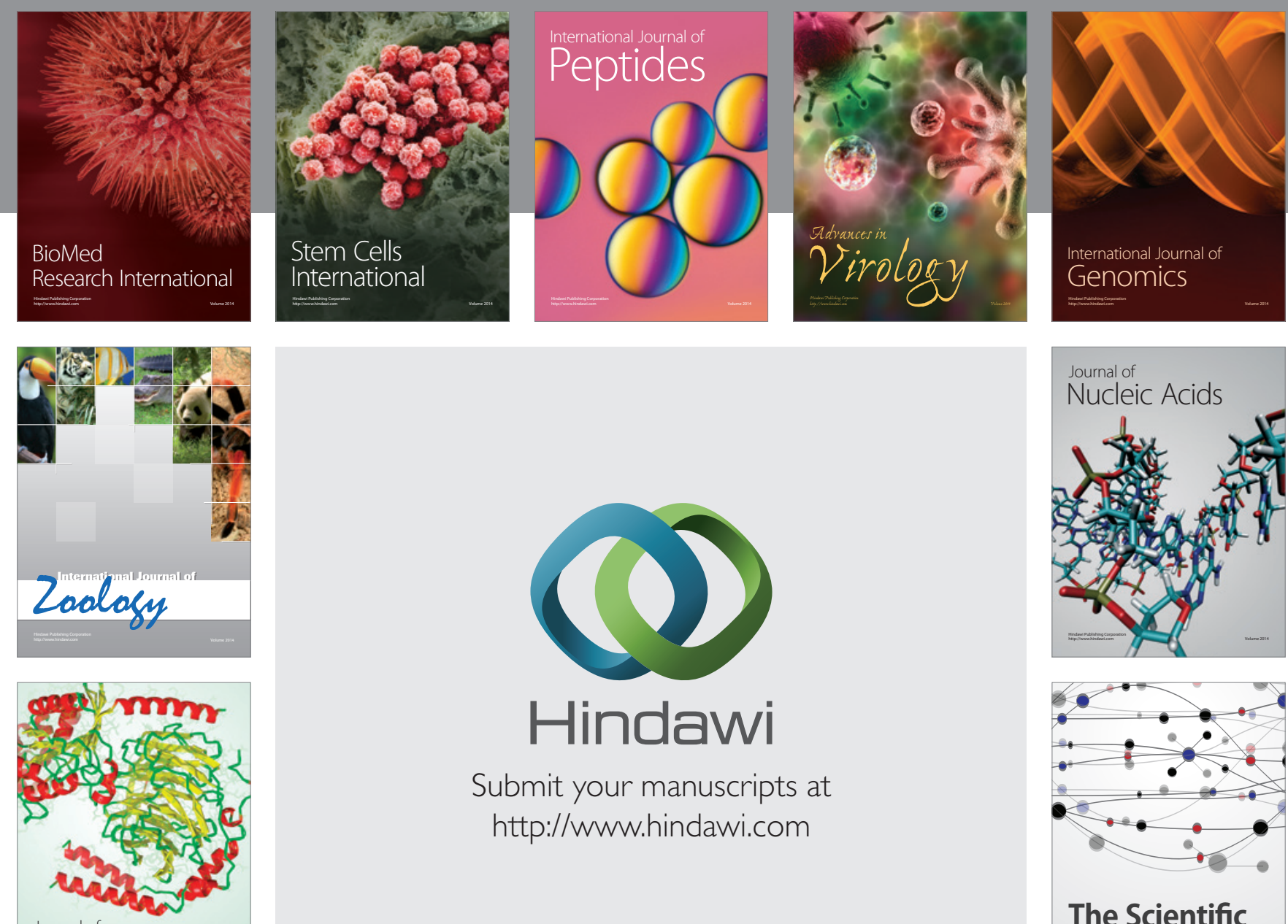

Submit your manuscripts at

http://www.hindawi.com

Journal of
Signal Transduction
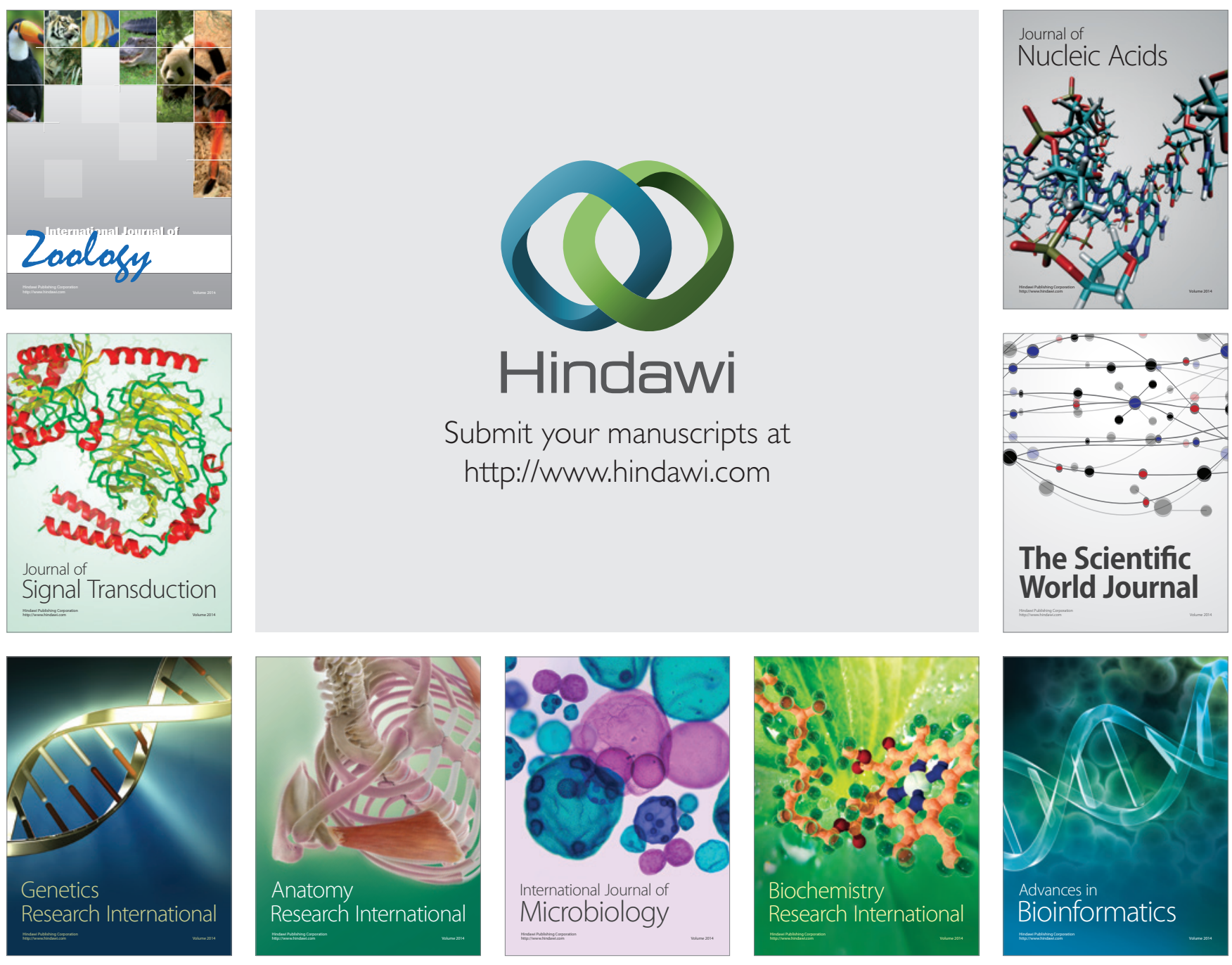

The Scientific World Journal
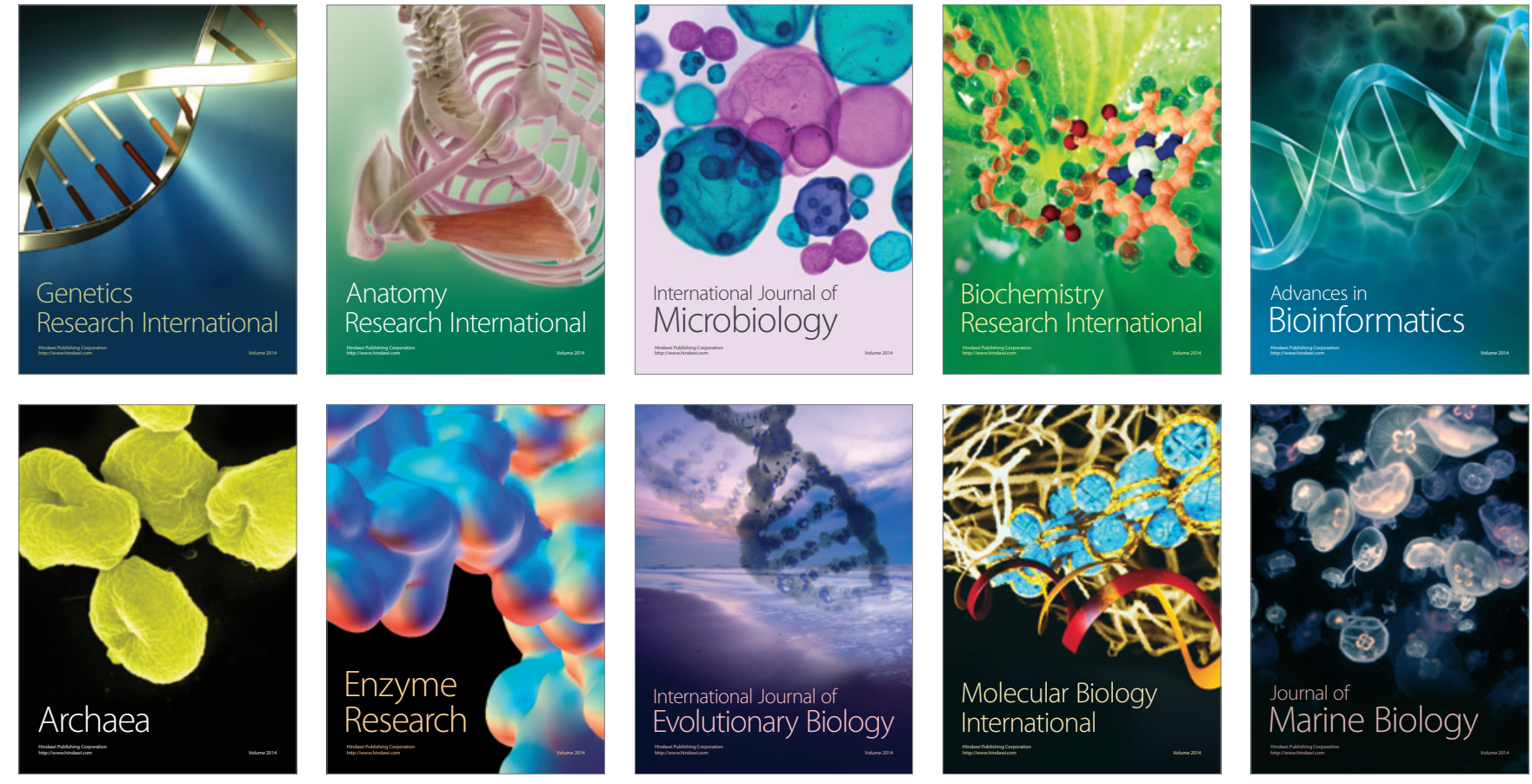